\title{
Functional Outcome of Neurotization to The Musculocutaneous Nerve in Traumatic Brachial Plexus Injury
}

Mohammad Azrul Bin Abdul Rashid ${ }^{1}$, Kamarul Ariffin Khalid ${ }^{1}$, Raffael Ismail ${ }^{1}$

${ }^{1}$ Department of Orthopaedics, Traumatology and Rehabilitation, Kulliyyah of Medicine, International Islamic University Malaysia

Presenter: Mohammad Azrul Bin Abdul Rashid

Introduction: Neurotization procedures to the elbow flexors are commonly done in traumatic brachial plexus injury (BPI). The objective of this study was to evaluate the recovery of elbow flexors in patients who underwent neurotization procedure to musculocutaneous nerve in the panplexus and upper trunk BPI. Materials and Methods: This was a cross sectional study involving 70 patients who underwent neurotization to elbow flexor. A total of 31 patients $(44 \%)$ had panplexus injury and 39 (56\%) had upper trunk BPI. Elbow flexor motor power and post-operative Disabilities of the Arm, Shoulder and Hand (DASH) score were evaluated. Results: The mean age of the patients was 22.7 years. Patients with panplexus BPI underwent neurotization to the elbow flexor using spinal accessory nerve as a donor and patients with upper trunk BPI used either ulnar or median nerve as a donor. The results of elbow flexors recovery in panplexus BPI were good (MRC grade 4 and 5) in 11 patients (35.5\%) and poor in 20 patients $(64.5 \%)$. Conversely, the recovery of elbow flexors in upper trunk BPI were better with 28 patients $(71.8 \%)$. Good post-operative DASH score (score $<50$ points) were noted in 29 patients (74.4\%) with upper trunk BPI. Only seven patients $(22.6 \%)$ with panplexus BPI showed good post-operative DASH score. Majority of patients with panplexus BPI demonstrated poor recovery of elbow flexor and post-operative DASH score as compare to upper trunk BPI $(p=0.002)$. Conclusion: Overall, this study showed significantly better functional outcome of neurotization procedure to elbow flexor in upper trunk BPI than in panplexus BPI. 